\title{
Self-management in children labeled learning disabled
}

\author{
JOSEPH S. EDWARDS \\ University of Missouri, Kansas City, Missouri 64110
}

\begin{abstract}
Access to recess was used as a reinforcer to study the development of elementary self-management skills (being quiet and staying in one's seat) during a quiet period, without direct teacher supervision. A verbal report system confirmed by hidden observation was used to record the behavior of the children. Group, individual, and individual plus group contingencięs of reinforcement were utilized. Individual and individual plus group reinforcement contingencies were found to be the most effective procedures. Data are presented that clearly show children will submit reports of their own behavior that deny them access to reinforcement as well as report accurately on the behaviors of other children (even under threat). The children that were found to be responsible for the class losing privileges under group reinforcement contingencies were successfully managed by a peer and when they served as class monitor (sat at teacher's desk), they behaved appropriately.
\end{abstract}

Field applications of operant conditioning principles have largely used individual reinforcement contingencies rather than group reinforcement contingencies. Recently, however, several investigators have evaluated the use of group contingencies to reduce inappropriate behaviors in classroom settings (Hamblin, Hathaway, \& Wodarski, 1971; Schmidt \& Ulrich, 1969; Sulzbacher \& Houser, 1968 ) as well as increase appropriate behaviors (Hamblin et al., 1971; Long \& Williams, 1973). One study compared group vs. individual contingencies in the same children with reinforcement contingent upon appropriate behavior (Long \& Williams, 1973).

The two most relevant studies to the present report are those by Schmidt and Ulrich (1969) and Long \& Williams (1973). Both research groups used classroom settings and free time or free time plus gym time as the reinforcement. In the Schmidt and Ulrich study, free time and additional gym time were dependent on quiet study time (sound-level measurement) and later inappropriate out of seats. Both group behaviors immediately decreased with the introduction of the contingency. This paradigm was subsequently applied successfully to one child who persisted in out of seat behavior. Long \& Williams (1973) compared group to individual contingencies, using free-time reinforcement and found that group contingencies "appeared to be slightly more effective" (p. 465).

This study departs from the previous research by its focus on the use of pupils as full managers (without direct teacher supervision): (1) of their own behavior (out of seats and talk-outs), (2) who supplied an accurate verbal report of their behavior as well as others' behavior, and (3) who functioned as class monitor (sat at teacher's desk and recorded and reported class behavior directly to the teacher). Both group, individual, and group plus individual contingencies were used during an unsupervised quiet time preceding a recess period. The study was not designed specifically to assess group and individual contingencies but to determine the extent of behavior management possible with a young class of primary learning disability children.

\section{METHOD}

\section{Subjects}

Ten children (5-9 years) enrolled in a primary learning disability class of a large elementary and junior high school participated. The mean IQ as measured by the WISC and PPVT tests was 100 . Forty percent of the children were referred to this class because of behavior problems, $30 \%$ for academic deficiencies, and $30 \%$ for both reasons. This class was selected because it was the only special education class in the school and the class was reported to be unusually noisy and disobedient. Most of the children came from middle- and upper-middle-class families.

All children had 3.5 months experience working under an individual free-time reinforcement system for academic work. Under this system, the children had to produce perfect academic papers (with or without teacher help) to earn free time. This system effectively increased both the number of papers produced and the accuracy at which the papers were done.

\section{Apparatus}

The project was conducted in a typical classroom equipped with desks and materials for 10 to 12 students. The only unusual feature of the facilities were three-sided partitions ( $24 \times 16$ in.) bolted to each pupil's desk. The apparatus consisted of the school intercom system, recording sheets used by a team of two teachers, recording sheets specially constructed for the pupil monitors, and a timer. Special sheets for use by the monitors contained the first names of every class member, written in uppercase block letters, (which most children could read) with approximately $3 / 4$ in. space across the page for the child to tally in.

\section{Procedure}

This project started 15 weeks prior to the termination of the school year. All 10 children participated during all phases of the project. The group recess period that normally followed lunch was used as a reinforcer to study self-management skills (being quiet and remaining in one's seat) during a 15-min quiet period. 
Immediately following lunch, the students were taken back to their classroom and given the opportunity to select a book, toy, pencil and paper, crayons, etc. to work with during the quiet period. The teachers were never present during this period.

After each child had selected a task to do at his or her desk, the children were instructed that they were not to get out of their seats or talk out. The school intercom was checked for its usual loud click, indicating that someone is to talk or is listening in, and the switch was found, upon test, not to be audible to the children during quiet classwork periods and in programmed quiet time with one teacher present.

Out of seat activity was always checked visually by one or both teachers during the last $2-3 \mathrm{~min}$ of the quiet period at least once a week. Feet movements were easily detected through the intercom circuit when observation was not conducted. Visual observation of the classroom was made through a large window mounted in the door. The seating arrangement was a horizontal row of desks facing the door, so that no pupil could detect an observer watching unless he inappropriately got out of seat. A simple record of either/or was kept, since a frequency of one was all that was required to prevent access to the contingent recess period.

The recess contingencies for behavior during the quiet period were: (1) All pupils earn recess if no pupil talks out; (2) all pupils earn recess if no pupil talks out or gets out of seat; (3) all pupils earn recess if no pupil talks out or gets out of seat, and a verbal report by each member of the class; (4) only pupils who talk out or get out of seat lose the recess privilege, with a verbal report by each member; (5) pupil monitor (pupils took a weekly turn as monitors who recorded whether other pupils, as well as themselves, talked out or got out of seat); and (6) pupil monitor (selected by the teachers), only pupils who talk out or get out of seat lose the recess privilege; if all pupils earn recess each pupil receives a penny which, upon the collection of 10 , buys a bottle of pop.

This particular order of experimental conditions was used to permit comparisons of the effectiveness of the different reinforcement contingencies and in an effort to improve each class member's self-management skills. Reinforcement conditions (e.g., 1, 2, 3) were conducted for a short period of time because of their effectiveness in decreasing out of seat and talk-outs during the quiet period.

After the 15-min quiet period was over, the teachers asked each pupil, in the first two conditions, if he or she was out of seat or talked out during the quiet period. Then all pupils were asked if the statement made was correct. Unanimous pupil agreement was required before any action took place. Upon reaching such agreement (in comparison with teacher records) appropriate action took place according to the contingencies outlined above. The direct question procedure was changed to a voluntary report during and following Phase 3. Pupils initiated statements regarding whether or not they were out of seat or talked out during the last three conditions of the study. Unanimous pupil agreement, in conjunction with teacher records, was always required prior to determining who was permitted to go to group recess and who was denied this privilege. The unanimous voting procedure was of additional importance, since this procedure identified the specific child or children who got out of their seat. The intercom indicated that a child was out of seat, but the children themselves identified which child it was.

All 10 children, selected randomly, served for 1 week as class monitor in the fifth condition. The teachers selected monitors for Condition 6, so that between-condition comparisons were possible with six children and within-condition comparisons were possible with three children. These children were specifically rescheduled as monitors on the basis of the performance of the class in Condition 4: high, low, or erratic percentages of children earning recess.

\section{RESULTS}

Figure 1 presents data summarizing the percentage of children who earned access to contingent recess period during the six experimental conditions. Overall, the most effective procedures were: (1) individual contingency with verbal report (median of $90 \%$ earning recess each day) (Phase 4), (2) pupil monitor with verbal report and individual plus group penny contingency if all earn recess (median of $90 \%$ earning recess each day) (Phase 6), and (3) individual contingency only with pupil monitor and verbal report (median of $80 \%$ earning recess each day) (Phase 5). The least effective procedures were the group contingencies used in the first three conditions.

It is interesting to note that two of the manipulations produced the most dramatic changes. Introduction of the individual recess contingency following the group contingency produced an immediate increase in the number of children earning the recess opportunity. Following this condition, introduction of the pupil monitor system produced a reduction in the number of pupils earning recess. Monitors J.B., J.D., L.T., M.C., and P.F. maintained high levels of participation. The lowest overall level of children earning recess occurred

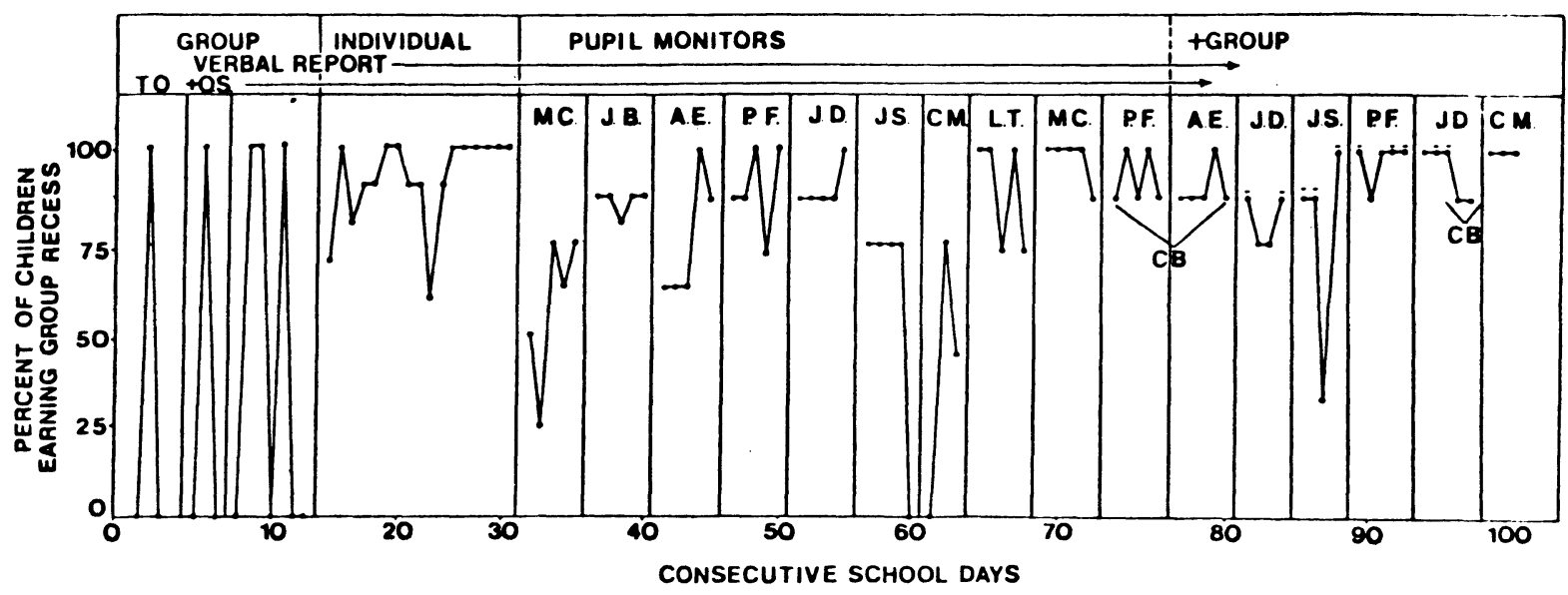

Figure 1. 
with two monitors (M.C. and C.M), who, overall, were themselves responsible for about $75 \%$ of all instances of an out of seat and talk-out. On the 2 days when no one earned recess, both monitors left the teacher's desk and engaged in conversation with the class.

Six monitors participated in both monitor conditions. Three monitors (J.D., M.C., P.F.) were rescheduled during the last two phases so that within-condition comparisons could be made. These monitors maintained higher levels of children earning recess the second time they were monitors. During the monitor period in the fifth condition, one child (C.M.) either got out of his seat or talked out on 14 days. The same child was found to be responsible for 4 days during the first monitor period in Condition 6, in which no pupil earned the group programmed penny. In the early part of this phase, C.M. denoted 7 days in which this child talked out. One pupil in the class requested and was given permission to sit with this child. On 6 of the 10 days, this child was successfully managed. Removal of this procedure was followed by 2 days of talking out. It is interesting to note, however, that when this child became monitor during the last 3 days of the school term, in no instance did he or any member of the class lose the recess privilege. This finding is worthy of mention since, in over $90 \%$ of the total monitor days in the last two phases of the study, monitors did not engage in inappropriate quiet time behaviors.

\section{DISCUSSION}

The purpose of this study was to determine if so-called young "primary learning disability children" could develop and maintain a fairly advanced level of self-management skill without direct teacher supervision. Six experimental conditions were successively altered in an attempt to generate and maintain appropriate self-management behaviors in a group situation.

The group contingencies alone (Phases 1-3), were found to be the least effective procedures. This contingency, however, when used with an individual contingency, was found to improve performance (Phase 6). This difference was found to be at tributable in part to two children, who together were responsible for $75 \%$ of the class sessions showing percentage scores less than $100 \%$ in these two conditions.

The most important finding of the study, from the vantage point of trying to understand and describe behavioral characteristics of young normal and exceptional children, revolves around the self-report recording system and the extent of involvement in honest reports, submitted vs. requested, resulting in the denial of privileges as well as reporting accurately on the behaviors of others. Evidence was collected that, through the behaviors of several of the children who spontaneously altered the report procedure, a "each of us who talked out or got out of seat report first" system generalized rapidly (within 2 weeks). All pupils followed this procedure. Reliability checks were performed when full quiet time was observed and listened to and when observations occurred briefly; in every instance agreement was $100 \%$. After the first verbal report period, the system took less than $5 \mathrm{~min}$ to complete. On that day one pupil threatened the class and it took $15 \mathrm{~min}$ to reach unanimity.

In addition to the development of self-report and some self-management skills, we found that several children (one was the boy who threatened the class, the other was the boy who initiated the volunteer report system) requested to manage the two children who were largely responsible for ro one earning a penny during the last experimental condition. These children were over $70 \%$ effective in their management efforts.

In spite of the use of modern education and psychological testing techniques, which unfortunately continue to lack the refinement of methods that are capable of precise description of specific learning disabilities, the results of this study clearly show that, in one sample of children diagnosed as "learning disability," quite sophisticated individual and social behavior skills can readily be generated and maintained. In addition, the results suggest that latitude prevailing in any management system should sensitively reflect and change when innovative and more sophisticated behaviors of the persons it is designed to serve are provided. This functional dependence between procedure and behavior makes adherence to a rigid experimental design impractical in many applied settings.

\section{REFERENCES}

Hamblin. R. T., Hathaway, C., \& Wodarski, J. Group contingencies. peer tutoring and accelerating academic achievement. In E. Ramp and B. L. Hopkins (Eds.). A new direction for education: Behavior analysis. 1971. Lawrence: University of Kansas, 1971. Pp. 41-53.

Long, J. D., \& Williams, R. L. The comparative effectiveness of group and individually contingent free time with intercity junior high school students. Journal of Applied Behavioral Analysis, 1973, 6, 465-474.

SChmidT, G. W., \& UlRICH, R. E. Effects of group contingent events upon classroom noise. Journal of Applied Behavioral Analysis, 1969, 2, 171-179.

Sulzbacher, S. I., \& Houser, J. E. A tactic to eliminate disruptive behaviors in the classroom: Group contingent consequences. American Journal of Mental Deficiencies. 1968. 73. 88-92.

(Received for publication March 21. 1976) 